\title{
Selected Aspects of the Application of Terrestrial Laser Scanning as a Tool to Support the Development of Rural Areas
}

\section{Introduction}

The aim of this paper is to present possibilities of using terrestrial laser scanning in work designed for comprehensive rural development. Due to the complexity of the issue, the science areas which have a significant impact on the planning process in rural areas were described. Existing scientific publications focused in a vertical way, showing the single issues. This publication provides a horizontal overview of current knowledge on the use of terrestrial laser scanning in rural development. In this paper, branches of agricultural, forestry and architecture were spoken.

\section{Agriculture}

A terrestrial laser scanning is very useful in precise agriculture. Agriculture as an important branch of the economy of each country requires the implementation of new technologies, as the basis for the development and better management of the rural area, while optimizing working capital. There are many scientific publications taking into discussions about using terrestrial laser scanning in agriculture, and they present advantages and disadvantages of using it [10]. To the main advantages, Tilly and co. belong accuracy, moreover, the simplicity and rapidity of data acquisition are specified. Research connected with using terrestrial laser scanning in the agriculture are focused on growing crop surface modeling (CSM) as a basis for monitoring the growth of various crops, modeling fields, and estimating fields [9, 10, 22].

* University of Agriculture in Krakow, Faculty of Environmental Engineering and Geodesy, Department of Agricultural Land Surveying, Cadaster and Photogrammetry, Krakow, Poland

** University of Agriculture in Krakow, Faculty of Environmental Engineering and Geodesy, Department of Geodesy, Krakow, Poland 
Hoffmeister and co. [9] studied the distribution of plant height based on wheat, barley, sugar beet and potatoes, using time-of-flight terrestrial laser scanner with a range of $2-1,000 \mathrm{~m}$. Depending on the size of the measured area the scanner could be mounted on a tripod and remain stationary throughout the measurement, or on a mobile device, using DGPS technology to precisely determine the location of the next measuring stations. Additionally, mounted digital camera was capable of capturing images, which were used to colouring or texturing a point cloud. As the result of work was the crop surface model, the crop volume model and crop elevation model resulting from the CSM performed in different time periods. A similar issue dealt with Tilly and co. [22], using a terrestrial laser scanning to rice growth monitoring, depending on the type of the rice fertilization. The measurement was dane three times at some intervals of the time, using the time-of-flight scanner, having a relatively large range. The result of the study was the crop surface model, which is defined as the difference between the DTM and DSM, based on the three-time measurement of the same area and then on the basis of differences between successive CSM was performed to determine the growth of rice (Fig. 1). CSM is defined as a surface model of an agricultural field.

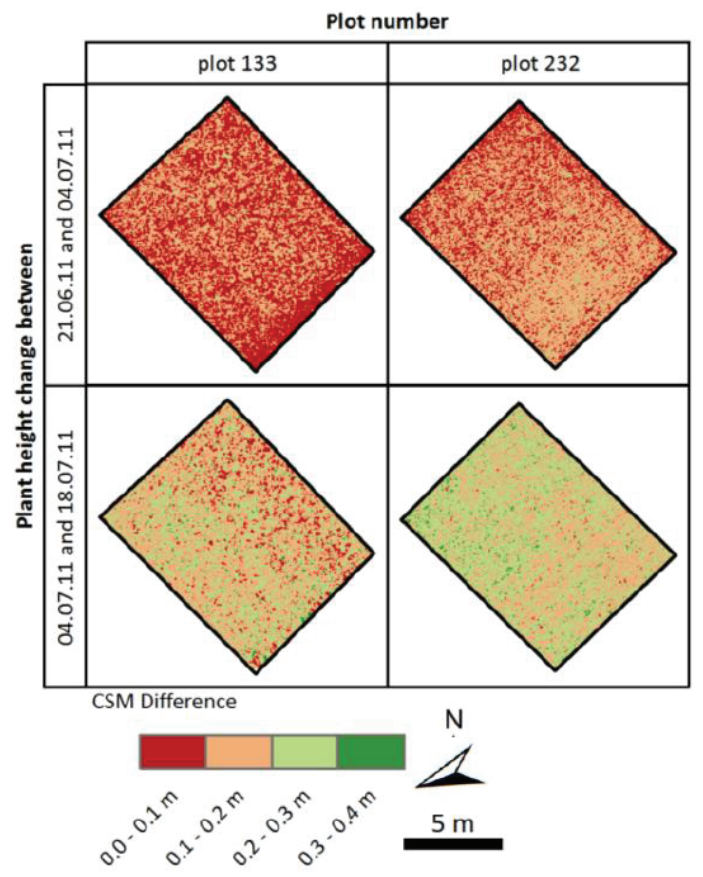

Fig. 1. Maps of height difference between two consecutive CSMs Source: [22]

To calculate the height of the plants, and compare them with the results measurement in subsequent sessions a common reference surface is needed. In order to 
obtain the reference surface which is similar to the real ground, the lowest points from point clouds and the points characterized by the lowest density are filtered. Terrestrial laser scanning, using appropriate computer software algorithms also can be used for automatic recognition of ears and estimating their size [10].

\section{Forestry}

Many scientific publications are interested in terrestrial laser scanning and the possibilities of using it in forestry. In contrast to using this method in agriculture in case the forestry can be indicated some limitations, which sometimes entirely exclude this method. Park et al. [13] specify, that accuracy of measurement can be ensured only in the case measurement small area with rare trees stands or in case single tree. Park et al. [13] and Thies and Spiecker [21] discuss about existing shadow effect, what causes the necessity of measurement from many positions. In addition to this, in forestry the troubles in tree shape recognition can be caused by moving of upper branches of a tree were discovered. Indirectly, the big limitation can be the relation between price and efficiency, so the terrestrial laser scanning often can be used only for research purposes [23]. The best results and the biggest benefits are achieved in measurement of a single tree, where can get information about position of a single tree in tree stand, thickness of the tree and damage to trunk [7, 23]. Moreover, after suitable filtering point clouds, in case measurement stand tree digital terrain model (DTM) can be created [23]. Many papers show that most of the processes in forestry are aimed to automatic recognition trees. Aschoff et al. [2] write about automatic fitting a circle in groups of points, Pfeifer and Winterhalder [14] write about fitting a cylinder in the trunk of the tree. Another parameter computing in base on data from terrestrial laser scanner is tree height, determine can be difficult in the dense tree stand [1,21]. Based on data from TLS, it is also possible to get information about breast height and thickness of a tree Simonse et al. [17].

\section{Architecture}

The research connected with using TLS in architecture can be divided into two groups. First type of work is involved to optimization and automation in data use, has aimed lower costs of using terrestrial laser scanning and also saving time during data use. The second type includes comparison commonly used techniques of measurements like tacheometry and photogrammetry with TLS. Realized measurement of the medieval castle was using three of these method. Grussenmeyer et al. [8] during comparison focused on contour lines of windows, which are characterized by the complexity of construction for these buildings. Field test was the facade of 21 windows, for which the measurement was done. The shape 
of the subject and frame the distance between successive frames were analyzed. Tacheometry proved to be the least accurate of the measurement the circular and chamfered parts in contrast to terrestrial laser scanning. The next stage was to create a mesh of triangles based on data from photogrammetry and laser scanning. The results showed that the grid based on the data obtained from the laser scanning was regular, but have not been recognized as some characteristics of the edges or corners. An important limitation of terrestrial laser scanning is the difficulty in measuring the linear elements, derived edges are the result of interpolation and generalization of the point cloud. Mesh of triangles formed from terrestrial photogrammetry kept any discontinuity object. In order to obtain a complete 3D model of the object is indicated for a compilation of different approaches, such as the analysis of existing plans and maps, terrestrial laser scanning, photogrammetry, computer visualization [6]. Research Fabris et al. [5] present a comparison the surface models of block brick obtained from time of flight scanner measurement, short-range scanner measurement, terrestrial photogrammetry and traditional total station. The results were presented. A model made from ground-based laser scanner measurements was compared with a model created on the basis of 50 points was measured by tacheometry. The standard deviation was $2.24 \mathrm{~mm}$, the accuracy of the scanner was higher than that reported by the manufacturer, what is a result of the short distance ( 5 meters). The second comparison concerned the model obtained from the terrestrial photogrammetry with laser scanning and tacheometry. The field test was comprised of brick blocks with a length of 3 meters, where the stereoscopic photo had the big overlap between subsequent photos was $95 \%$, the overlap between the first and the third image was $90 \%$ and, thus, the overlap between the first and the last image was $40 \%$. Such a large overlap was designed to avoid the presence of shadow zones in the joint between the blocks. In the case of the model created from images with overlap of $80 \%$ and less or tacheometry model the standard deviation was $1 \mathrm{~mm}$. The best relationship between the occurrence of shadow zone and the accuracy achieved by using the overlap equal to $60 \%$. Short-range scanner was used for architectural details. Grussenmeyer et al. [8], Fabris et al. [5] from measurements using all three techniques indicate the need for their integration in order to achieve complexity research. Tacheometry should be used for getting geodetic minor control points, used to match subsequent measurement or for measuring the control points on the building elevation. In addition to this, tacheometry can be used to achieve primary building outlines [8]. Photogrammetry provides high accuracy measurement of small parts, architectural details and places inaccessible to the laser scanner [5]. Fabris et al. [5] at the same time shows the high accuracy of terrestrial laser scanning, high granularity of data, the ability to adjust LoD (Level of Detail) to the nature of the object, the possibility of texturing. The drawback could be the formation of the measurement noise and shadow zones which raises the need for the measurement of several measuring stations. A comparison of measurement methods currently used in the documentation of cultural heritage was presented in the Table 1 [18]. 
Table 1. Comparison of methods

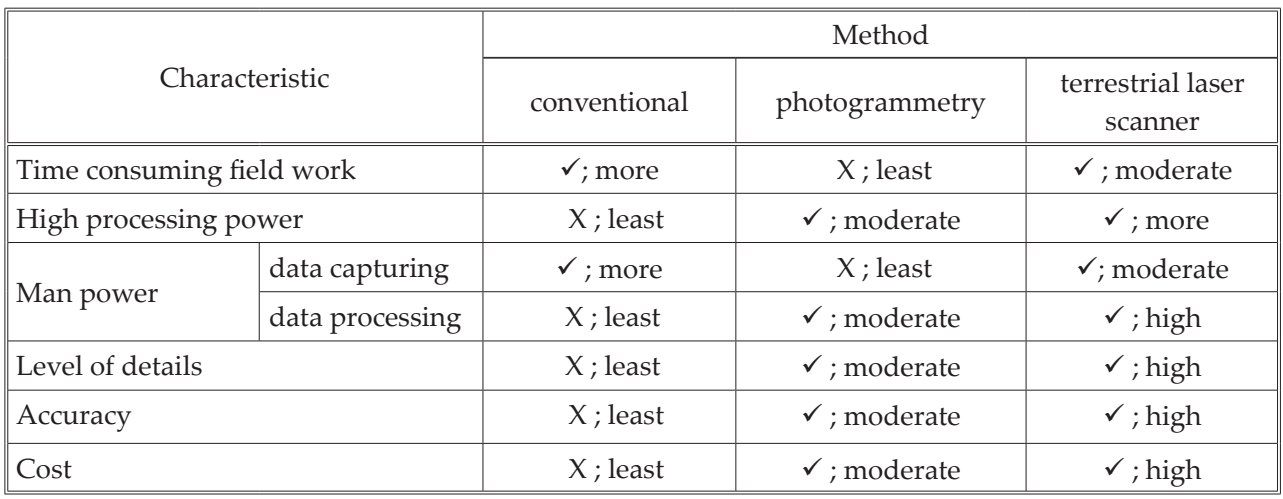

$X$ - the worst method

$\checkmark$ - better and the best method

Source: based on [18]

Taking into account the advantages of terrestrial laser scanning, using in architecture comes down to creating architectural documentation, implementation of 3D models of buildings, create interactive visualizations, and to support the reconstruction of buildings [18]. Particularly noteworthy is the use of terrestrial laser scanning to create 3D models of buildings. Taking into account the relation between the time of field work and the office work, noted the necessity of automation the process of compiling the data, in particular in the field of automatic detection of buildings. Traditional methods are based on data from a GIS database, and aerospace and terrestrial photogrammetry. Aerial Photogrammetry provides an images of roofs of buildings, details are collected by terrestrial photogrammetry. In addition, the orthogonal digital images allow applying textures. Given the number and complexity of objects traditional methods are time consuming and very expensive [16]. In same case aerial photos can be replaced on satellite photos, what is a huge facilitation. According to [16] 3D city models are successfully used in urban planning, bringing the concepts of spatial solutions from 2D space, represented by map to 3D space built on the basis of data from terrestrial laser scanning. An important advantage of terrestrial laser scanning is that it provides full information about the geometry of the building in a very fast and accurate way. The high density point cloud may be expressed: in the local scanner coordinate system or in the global coordinate system. At the same time, it is valuable material for the automatic reconstruction process of buildings. According to [16] the reconstruction process can be divided into three steps. First of all it is feature recognition, where building features such like: walls, windows, doors, etc. are extracted. Then, it is model fitting, where recognized features are fitted into simple geometric shapes. Finally, it is model reconstruction, where models are combined from fitted geometric shapes and are matched to each other by means of suitable algorithms. 
The feature recognition is started from the segmentation, where the point cloud is categorization. Points, which belong to a single plane or to the one region, are included in a group, where each group is considered as a potential feature of the building and analyzed at a later stage. Each group is assigned by properties such as: size, position, direction, topology. An important element is to determine the relative position of the respective groups. Otherwise segmentation can be defined as a labeling of a point cloud. Segmentation algorithm is proposed by G. Vosselman. This algorithm introduces the concept of the based plane, which consists of a group of contiguous points. That points are consistent with the distance criterion and the plane equation. According to the author, the purpose of segmentation is that each segment/group should be represented by the characteristic feature of the building and each characteristic feature should be represented by the segment/group. Segmentation results, due to measurement noise, cannot be considered absolutely correctly. The main problem is the qualification of one feature to several segments/ groups or lack of qualification feature of any group. Recognition algorithm base on the basic knowledge about the geometry of the building and the mutual relationship between the planes.

In addition, the parameters such like: size, position, direction, topology are analyzed. Pu [15] indicates that in order to achieve higher accuracy, it is important the sequence of recognized features. First of all, it should be recognized large surface objects such like: walls, roofs and turn. Finally, the small elements such as parapets. Automation of compiling the data from terrestrial laser scanning may also apply to match individual point clouds without the targets [4].

Terrestrial laser scanner measures points at certain regular intervals. These points are defined by the angle of deflection of the laser beam in horizontal and vertical direction. During the measurement of the scanner (which is stationary mounted on a tripod we obtain points in the local coordinate system of the scanner. These points can be stored in the form of a regular raster images. The advantage of that solution is the possibility of using dedicated algorithms for 2D images to transfer data to the 3D. Automation of matching point clouds also requires the creation of the base area, which is created based on $x y z$ data points stored in raster images.

An important step is to define the parameters of the transformation, translation and rotation for each point cloud to their each other matching. Proposed by Dold and Brenner [4], the method is sufficiently accurate for further work on the point cloud for the purposes of planning, creating a virtual reality video game environments, monitoring historical documentation. Wide possibilities of using terrestrial laser scanning in architecture, should be supported by economic. Some authors, which are studying the modeling of 3D objects, unanimously point to the need for automation as a means to reduce costs and increase efficiency $[4,11,15,16,20]$.

As a common example of using terrestrial laser scanning we can provide measurement of hydropower water dams, which are extremely important objects for shaping the landscape. The authors conducted research about the water dam in Solina, to 
investigate the geometry of the runoff. The paper shows two methods for creating cross sections of runoff: graphical method (by using Leica Cyclone software and Microstation V8i), and a statistical method (by using Statistica 10) Cartesian coordinates (X, Y) obtained from text files for nine selected parts of point clouds were imported to the new worksheet. Each part of point cloud was selected in Cyclone 8.0 software. For each part we made a graph of the dispersion of the quantile (the $X$ value with respect to $Y$ value) to evaluate symmetry of the empirical distributions of two coefficients.

As a result of the analysis, the authors obtained - for nine selected slices of point clouds - nine cross sections of runoff of water dam in an automatic, statistical way, and nine cross sections of runoff of water dam in visually way by the investigator. Then, authors measured the distance between the outermost cross sections in characteristic places on $X$ axis $(-20,-10,0,10)$ The results present Table 2.

Table 2. The distance between outermost cross sections

\begin{tabular}{|c|c|c|c|c|c|c|c|c|c|c|}
\hline \multicolumn{3}{|c|}{$\begin{array}{l}\text { Characteristic } \\
\text { points }\end{array}$} & \multicolumn{2}{|c|}{-20} & \multicolumn{2}{|c|}{-10} & \multicolumn{2}{|l|}{0} & \multicolumn{2}{|c|}{10} \\
\hline \multirow{2}{*}{ 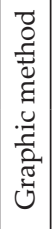 } & \multirow{2}{*}{ 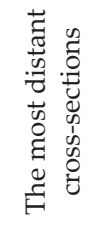 } & \multirow{2}{*}{ 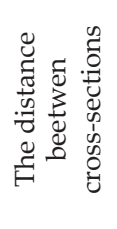 } & $\begin{array}{l}\text { cross- } \\
\text { section } 1\end{array}$ & \multirow{2}{*}{0.21} & $\begin{array}{l}\text { cross- } \\
\text { section } 1\end{array}$ & \multirow{2}{*}{0.19} & $\begin{array}{l}\text { cross- } \\
\text { section } 1\end{array}$ & \multirow{2}{*}{0.19} & $\begin{array}{l}\text { cross- } \\
\text { section } 1\end{array}$ & \multirow{2}{*}{0.19} \\
\hline & & & $\begin{array}{l}\text { cross- } \\
\text { section } 8\end{array}$ & & $\begin{array}{l}\text { cross- } \\
\text { section } 8\end{array}$ & & $\begin{array}{l}\text { cross- } \\
\text { section } 8\end{array}$ & & $\begin{array}{c}\text { cross- } \\
\text { section } 8\end{array}$ & \\
\hline \multirow{2}{*}{ 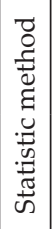 } & \multirow{2}{*}{ 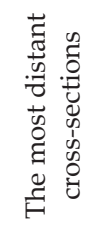 } & \multirow{2}{*}{ 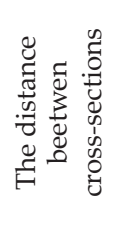 } & $\begin{array}{l}\text { cross- } \\
\text { section } 1\end{array}$ & \multirow{2}{*}{0.19} & $\begin{array}{l}\text { cross- } \\
\text { section } 1\end{array}$ & \multirow{2}{*}{0.14} & $\begin{array}{l}\text { cross- } \\
\text { section } 1\end{array}$ & \multirow{2}{*}{0.12} & $\begin{array}{l}\text { cross- } \\
\text { section } 1\end{array}$ & \multirow{2}{*}{0.12} \\
\hline & & & $\begin{array}{c}\text { cross- } \\
\text { section } 8\end{array}$ & & $\begin{array}{l}\text { cross- } \\
\text { section } 7\end{array}$ & & $\begin{array}{l}\text { cross- } \\
\text { section } 8\end{array}$ & & $\begin{array}{l}\text { cross- } \\
\text { section } 7\end{array}$ & \\
\hline
\end{tabular}

Source: based on [12]

On the basis of Table 2 it can be seen that the largest distance difference occurs between a section 1 and a section 8 for both the statistical and graphical method. Moreover, based on the values obtained have noted that the scattering cross section is larger in the case of the use of graphical methods. The average difference in distance between the cross sections for the graphic method is $0.20 \mathrm{~m}$, and for the statistical method $0.14 \mathrm{~m}$ The values indicate greater unification of the shape of the trailing firewall for statistical method [12].

The statistical method is applicable for determining the cross sections of for the elements of a simple geometry. By automating the process of fitting a line (curve) in a fragment of the point cloud is excluded subjectivity of the researcher. In the 
graphic method, individual investigator assessment forms the basis for the designation of the section line, which is good for the structural elements of buildings with complex geometry [12].

\section{Summary}

The current knowledge on terrestrial laser scanning points to the possibility of using this technique as a tool to support the comprehensive development of rural areas. Examined areas such as agriculture, forestry, architecture, have a direct influence on the spatial order as a basis for optimal utilization of the existing area and its resources. Terrestrial laser scanning is therefore an important support for traditional methods based on 2D space, providing accurate three-dimensional data.

Particular attention should be paid to scientific work in the field of comparative terrestrial laser scanning and terrestrial photogrammetry. P. Grussenmeyer et al. [8] indicate advantages of terrestrial photogrammetry in the research of cultural heritage objects, which include: a high level of detail of the image-objects, low cost and speed of data acquisition.

The advantage of terrestrial laser scanning is the acquisition of spatial data which is an exact representation of the object. A significant limitation, in the case of an architectural complex may be difficulty in clear interpolation edge. The best results are achieved, by using both methods on the principle of complementarities. [8]. When we compare the terrestrial laser scanning with photogrammetry ground, we should pay attention to the precision guaranteed by the measuring equipment, as it is shown in Table 3.

Table 3. Overview of the instruments used for acquisition and summary of the amount of data recorded

\begin{tabular}{||l|l|l|l||}
\hline \multicolumn{1}{|c|}{ Data } & \multicolumn{1}{|c|}{ Instrument } & \multicolumn{1}{c|}{ Amount of data } & \multicolumn{1}{c|}{ Accuracy } \\
\hline \hline Laser & Trimble GX & $\begin{array}{l}25 \text { million points all around } \\
\text { the castle + inside }\end{array}$ & $7 \mathrm{~mm}$ at $100 \mathrm{~m}$ \\
\hline Tacheometer & Trimble 5500 & $\begin{array}{l}400 \text { points }(1 \text { day); eastern } \\
\text { façade (windows), inside and } \\
\text { outside }\end{array}$ & $\begin{array}{l}+/-3 \mathrm{~mm}+3 \text { ppm; spot } \\
\text { diameter: } 3 \mathrm{~mm} \text { at } 50 \mathrm{~m}\end{array}$ \\
\hline Camera & $\begin{array}{l}\text { Zeiss SMK } \\
\text { (analogous) }\end{array}$ & $\begin{array}{l}50 \text { stereoscopic models; } \\
\text { lower parts of the castle } \\
\text { (whole courtyard and } \\
\text { adjacent parts of towers) }\end{array}$ & $\begin{array}{l}\text { 200 GCPs with accuracy } \\
\text { about }+/-5 \text { mm in X,Y,Z }\end{array}$ \\
\cline { 2 - 5 } & $\begin{array}{l}\text { Canon EOS 5D } \\
\text { (digital) with } \\
\text { different lenses }\end{array}$ & $\begin{array}{l}\text { 100 photographs; all around } \\
\text { the castle (exterior facades }+ \\
\text { donjons) }\end{array}$ & $\begin{array}{l}\text { Image pixel size: } 8.24 \mu \mathrm{m} ; \\
\text { object pixel size: } \\
\text { approx. } 1 \mathrm{~cm}\end{array}$ \\
\hline
\end{tabular}

Source: [8] 
At the same time M. Fabris et al. say, that the accuracy depends primarily on the distance between a digital camera and the object. When we compare the terrestrial photogrammetry and terrestrial laser scanning, we should refer to the radiometric quality. K. Pyka [17] says, that if the basic issue of remote sensing is the reconstruction of electromagnetic radiation from the registered objects, the radiometric quality measure is the ratio of the luminance of energy facilities to radiation intensity, which is measured by a detector. Both the light beam digital photogrammetry and the laser beam in case of laser scanning are a carrier of information. The light beam shines on the object, and the next is recorded by digital cameras or photosensitive material of analog cameras allows you to grab an image of the test object. The recorded information is about intensity of light and its color. In the case of terrestrial laser scanning the laser beam, provides information about the spatial position of the measured points.

\section{References}

[1] Aschoff T., Spiecker H.: Algorithms for automatic detection of trees in laser scanner data. The International Archives of Photogrammetry, Remote Sensing and Spatial Information Sciences, vol. XXXVI-8/W2, 2004, pp. 71-75.

[2] Aschoff T., Thies M., Spiecker H.: Describing forest stands using terrestrial laser scanning. The International Archives of Photogrammetry, Remote Sensing and Spatial Information Sciences, vol. XXXV-B5, 2004, pp. 237-241.

[3] Bienert A., Scheller S., Keane E., Mullooly G., Mohan F.: Application of terrestrial laser scanners for the determination of forest inventory parameters. Proceedings. International Workshop 3D Remote Sensing in Forestry, Vienna, $14^{\text {th }}-15^{\text {th }}$ Feb. 2006, Session 2b, pp. 55-60.

[4] Dold C., Brenner C.: Automatic matching of terrestrial scan data as a basis for the generation of detailed 3D city models. The International Archives of Photogrammetry, Remote Sensing and Spatial Information Sciences, vol. XXXV-B3, 2004, pp. 1091-1096.

[5] Fabris M., Achilli V., Artese G., Boatto G., Bragagnolo D., Concheri G., Meneghello R., Menin A., Trecroci A.: High resolution data from laser scanning and digital photogrammetry terrestrial methodologies, test site: an architectural surface. The International Archives of Photogrammetry, Remote Sensing and Spatial Information Sciences, vol. XXXVIII-3/W8, 2009, pp. 43-48.

[6] Gonzo L., El-Hakim S., Girardi S., Picard M., Whiting E.: Photo realistic $3 D$ reconstruction of castle with multi-sources image based techniques. The International Archives of Photogrammetry, Remote Sensing and Spatial Information Sciences, vol. XXXV-B5, 2004, pp. 114-119.

[7] Gorte B., Pfeifer N., Structuring laser-scanned trees using 3D mathematical morphology. The International Archives of Photogrammetry and Remote Sensing, vol. XXXV-B5, 2004, pp. 929-933. 
[8] Grussenmeyer P., Landes T., Voegtle T., Ringle K.: Comparison methods of terrestrial laser scanning, photogrammetry and tacheometry data for recording of cultural heritage buildings. The International Archives of the Photogrammetry, Remote Sensing and Spatial Information Sciences, vol. XXXVII-B5, 2008, pp. 213-218.

[9] Hoffmeister D., Curdt C., Tilly N., Bendig J.: 3D terrestrial laser scanning for field modelling. Workshop on Remote Sensing Methods for Change Detection and Process Modelling, 18-19.11.2010, Cologne, Kölner Geographische Arbeiten, H.92, 2010, pp. 25-30.

[10] Lumme J., Karjalainen M., Kaartinen H., Kukko A., Hyyppä J., Hyyppä H., Jaakkola A., Kleemola J.: Terrestrial laser scanning of agricultural crops. The International Archives of the Photogrammetry, Remote Sensing and Spatial Information Sciences, vol. XXXVII-B5, 2008, pp. 563-566.

[11] Mendy S., Chen W.: Application of terrestrial laser scanning in 3D reconstruction of building models. $7^{\text {th }}$ ISPRS Student Consortium and WG VI/5 Summer School, 2011.

[12] Mitka B., Biłka P., Pluta M.: Wykorzystanie nowoczesnych technik pomiarowych w monitorowaniu dużych obiektów hydrotechnicznych. Episteme Czasopismo Naukowo-Kulturalne, 2013, pp. 437-443.

[13] Park H., Lim S., Trinder J., Turner R.: 3D surface reconstruction of terrestrial laser scanning data for forestry. Geoscience and Remote Sensing Symposium (IGARSS), IEEE International, 2010, pp. 4366-4369.

[14] Pfeifer N., Winterhalder D.: Modelling of tree cross sections from terrestrial laser scanning data with free-form curves. The International Archives of Photogrammetry, Remote Sensing and Spatial Information Sciences, vol. XXXVI-8/W2, 2004, pp. 76-81.

[15] $\mathrm{Pu}$ S.: Generating building outlines from terrestrial laser scanning. The International Archives of the Photogrammetry, Remote Sensing and Spatial Information Sciences, vol. XXXVII-B5, 2008, pp. 451-456.

[16] Pu S., Vosselman G.: Automatic extraction of building features from terrestrial laser scanning. The International Archives of the Photogrammetry, Remote Sensing and Spatial Information Sciences, vol. XXXVI-5, 2006.

[17] Pyka K.: Porównanie jakości radiometrycznej zdjęć lotniczych wykonanych kamera analogowa $i$ cyfrowa. Archiwum Fotogrametrii, Kartografii i Teledetekcji, vol. 17, 2008, pp. 537-545.

[18] Setan H., Majid Z., Chin Ch., Wei Ch.: Terrestrial laser scanning for cultural heritage documentation. Case study: The old palace, Seri Menanti. South East Asian Survey Congress, Kuala Lumpur, 2011.

[19] Simonse M., Aschoff T., Spiecker H., Thies M.: Automatic determination of forest inventory parameters using terrestrial laser scanning. Proceedings of the ScandLaser Scientific Workshop on Airborne Laser Scanning of Forests, 2003, pp. 251-257. 
[20] Susaki J.: Modelling of building from terrestrial laser scanning considering topology for occulusion. CIPA Symposium, Kyoto, Japan, 2009.

[21] Thies M., Spiecker H.: Evaluation and future prospects of terrestrial laser scanning for standardized forest inventories. The International Archives of Photogrammetry, Remote Sensing and Spatial Information Sciences, vol. XXXVI-8/W2, 2004, pp. 192-197.

[22] Tilly N., Hoffmeister D., Liang H., Cao Q., Liu Y., Lenz-Wiedemann V., Miao Y., Bareth G.: Evaluation of terrestrial laser scanning for rice growth monitoring. The The International Archives of the Photogrammetry, Remote Sensing and Spatial Information Sciences, vol. XXXIX-B7, 2012, pp. 351-356.

[23] Wencel A., Wężyk P., Zasada M.: Możliwości zastosowania naziemnego skaningu laserowego w leśnictwie. [in:] Zawiła-Niedźwiecki T., Zasada M. (red.), Techniki geomatyczne w inwentaryzacji lasu - potrzeby i możliwości, Wydawnictwo SGGW, 2008, pp. 77-89. 